\title{
FAKTOR - FAKTOR YANG MEMPENGARUHI PRODUKTIVITAS TENAGA KERJA PEMANEN SAWIT PADA PT. BIO NUSANTARA TEKNOLOGI, BENGKULU
}

\author{
(FACTORS - FACTORS AFFECTING PALM HARVESTERS \\ PRODUCTIVITY IN PT BIO NUSANTARA TECHNOLOGY, \\ BENGKULU)
}

\author{
Ronika Nainggolan, Agus Purwoko dan M. Zulkarnain Yuliarso \\ Jurusan Sosial Ekonomi Pertanian Fakultas Pertanian, Universitas Bengkulu
}

\begin{abstract}
Maintaining and promoting the development of agricultural sector must not be separated from the role of plantation sub-sector development. Plantation sub-sector which is part of the national development and one of the most important commodity in Indonesia's economy is palm oil. This research was executed at the palm oil harvesting workers in PT. Bio Nusantara Teknologi, Bengkulu regency on April - May 2010. The purposes of this research were: (1) to count the productivity of the palm oil harvesting workers and (2) to analyze the factors that influence the productivity of the palm oil harvesting workers in PT. Bio Nusantara Teknologi Bengkulu. The amount of 121 daily payment workers was taken from 10 afdelling by stratified random sampling. The research showed that the productivity of the palm oil harvesting workers was 130,314 $\mathrm{kg} /$ day. While, factors that affected the productivity of the palm oil harvesting workers were workers' age and the amount of burden dependency family.
\end{abstract}

Keywords: the palm oil harvesting workers, productivity

\section{PENDAHULUAN}

Pembangunan sektor pertanian merupakan bagian integral dari Pembangunan Nasional dimana perkembangan pertanian memiliki makna sektoral dalam meletakkan dasar yang kokoh bagi perekonomian bangsa. Untuk mempertahankan serta meningkatkan perkembangan sektor pertanian tentunya tidak terlepas dari peranan perkembangan sub sektor perkebunan. Salah satu komoditi perkebunan terpenting dalam perekonomian Indonesia adalah kelapa sawit. Sebagai produk utama perkebunan kelapa sawit merupakan salah satu komoditas strategis sebagai penghasil devisa utama negara dari sektor non migas. Usaha peningkatan produksi perkebunan kelapa sawit diarahkan agar 
benar-benar dapat berfungsi sebagai penghasil devisa, meningkatkan kesempatan kerja dan peningkatan pendapatan serta taraf hidup petani.

Tenaga kerja merupakan salah satu faktor produksi yang penting pada subsektor perkebunan kelapa sawit disamping faktor produksi tanah, modal, dan manajemen, karena tenaga kerja amat menentukan didalam suatu proses kerja. Suatu pekerjaan pada prinsipnya tidak akan dapat berjalan dengan semestinya tanpa adanya tenaga kerja. Bahkan lat-alat produksi yang bagaimana pun canggihnya tidak akan bergerak dengan sendirinya tanpa adanya tenaga kerja. Sementara itu, keterbatasan lapangan pekerjaan dan masih rendahnya keterampilan menyebabkan penawaran tenaga kerja di Indonesia relatif tidak terbatas, jika dibandingkan dengan faktor produksi lainnya (Yuliarso, 1998).

Untuk mencapai produksi yang tinggi tentunya peranan tenaga kerja dalam suatu perusahaan menjadi faktor yang sangat mendukung dalam meningkatkan produktivitas. Dengan meningkatkan produktivitas maka akan terjadi peningkatan langsung pada standar hidup (Setiowati, 2007). Produktivitas tenaga kerja berkaitan erat dengan kuantitas produksi yang akan dihasilkan. Dengan kata lain, apabila produktivitas yang dihasilkan oleh tenaga kerja yang digunakan tinggi akan menghasilkan produksi yang tinggi pula (Sinungan, 1992; Mardiana, 2001; dan Daniar, 2006). Selanjutnya diterangkan bahwa rendahnya produktivitas dalam suatu perusahaan disebabkan oleh dua faktor, yakni (1) karena kemampuan tenaga kerja yang tersedia memang rendah dan (2) karena perusahaan tidak mempunyai sistem motivasi yang baik bagi produktivitas karyawan.

PT. Bio Nusantara Teknologi merupakan salah satu perkebunan kelapa sawit di Propinsi Bengkulu yang memberikan kesempatan kerja yang cukup besar, khususnya untuk kegiatan pemanenan buah sawit. Kegiatan ini secara fungsional mempunyai peranan yang relatif besar karena banyak atau sedikitnya hasil panenan akan sangat menentukan hasil produksi akhir. Dalam hal ini, dapat dikatakan bahwa produksi perusahaan sangat tergantung kepada produktivitas kerja dari pemanen sawit itu sendiri. Penelitian ini bertujuan untuk: (1) menghitung tingkat produktivitas tenaga kerja pemanen sawit PT. Bio Nusantara Teknologi Bengkulu dan (2) menganalisa faktor-faktor yang mempengaruhi produktivitas tenaga kerja pemanen sawit.

\section{METODE PENELITIAN}

\section{Lokasi, Data, dan Penentuan Responden}

Penelitian ini dilakukan pada PT. Bio Nusantara Teknologi Bengkulu yang berlokasi di Kec. Pondok Kelapa, Kab. Bengkulu Utara, karena perusahaan ini merupakan salah satu perusahaan perkebunan yang memperkerjakan tenaga kerja harian tetap (KHT). Data primer diperoleh langsung dari karyawan harian tetap pemanen sawit melalui wawancara langsung dengan menggunakan kuisioner. Sementara, data diperoleh dari literatur-literatur atau pustaka yang 
terkait yang ada hubungannya dengan penelitian. Sebanyak 121 tenaga KHT diambil secara stratified random sampling dari seluruh tenaga KHT yang tersebar dalam 10 afdelling.

\section{Analisis Data}

Untuk mengetahui besarnya produktivitas dari tenaga kerja pemanen sawit di PT Bio Nusantara Teknologi ditentukan dengan mengadopsi rumus dari Sedarmayanti (2001) sebagai berikut:

Produktivitas $=$

kelebihan hasil panen buah sawit segar (premi) dalam $(\mathrm{Kg})$

$$
\text { jumlah hari kerja (hari) }
$$

Alat analisis yang digunakan dalam penelitian ini adalah analisis regresi linier berganda. Analisis ini digunakan unutk menganalisis faktor-faktor yang diduga mempengaruhi produktivitas tenaga kerja pemanen sawit. Dalam hal ini produktivitas tenaga kerja pemanen sawit diduga sebagai fungsi dari umur pemanen $\left(X_{1}\right)$, jumlah tanggungan keluarga $\left(X_{2}\right)$, pendidkan formal $\left(X_{3}\right)$, umur tanaman $\left(X_{4}\right)$, dan pengalaman kerja $\left(X_{5}\right)$. Secara matematis dirumuskan dalam persamaan:

$$
Y=a+b_{1} X_{1}+b_{2} X_{2}+b_{3} X_{3}+b_{4} X_{4}+b_{5} X_{5}+e
$$

dimana $Y=$ produktivitas $\left(\mathrm{kg} /\right.$ hari), $X_{1}=$ umur pemanen (tahun), $X_{2}=$ jumlah tanggungan keluarga (orang), $X_{3}=$ pendidikan formal (tahun), $X_{4}=$ umur tanaman (tahun), $X_{5}=$ pengalaman kerja (tahun), $a=$ intersep, $b_{1}-b_{5}=$ koefisien regresi, $\mathrm{e}=$ kesalahan penggangu

Untuk mengetahui apakah variabel-variabel bebas secara bersama-sama berpengaruh terhadap variabel terikat dilakukan uji $\mathrm{F}$ pada taraf kepercayaan $(95 \%)$. Sementara untuk mengetahui pengaruh masing-masing variabel bebas terhadap variabel terikat, maka dilakukan uji $\mathrm{t}$ (t-test) dengan tingkat kepercayaan $95 \%(\alpha=0,025)$.

\section{HASIL DAN PEMBAHASAN}

\section{Produktivitas Tenaga Kerja Pemanen Sawit}

Standar pokok atau basis panen yang harus dipenuhi oleh pemanen setiap harinya di PT. Bio Nusantara Teknologi Bengkulu yaitu umur tanaman 12 tahun basisnya $750 \mathrm{~kg} /$ hari, umur tanaman 18 tahun basisnya $700 \mathrm{~kg} /$ hari dan umur tanaman 24 tahun basisnya $650 \mathrm{~kg} /$ hari. Kelebihan hasil panenan dari standar pokok dihitung sebagai premi produksi dan premi produksi ini yang diperhitungkan sebagai produktivitas pemanen. 
Tabel 1. Produktivitas pemanen sawit berdasarkan umur tanaman pada PT. Bio Nusantara Teknologi Bengkulu

\begin{tabular}{ccc}
\hline $\begin{array}{c}\text { Umur Tanaman } \\
\text { (Tahun) }\end{array}$ & $\begin{array}{c}\text { Jumlah Pemanen } \\
\text { (Orang) }\end{array}$ & $\begin{array}{c}\text { Rata-rata Produktivitas (Premi Produksi) } \\
\text { Pemanen }(\text { Kg } / \text { hari) }\end{array}$ \\
\hline 12 & 59 & 133,46 \\
18 & 37 & 126,27 \\
24 & 25 & 129,60 \\
\hline
\end{tabular}

Sumber: Data primer diolah, 2010

Tabel 1 menunjukkan bahwa rata-rata produktivitas (premi) pemanen pada tanaman umur 12 tahun adalah sebesar 133,46 Kg/hari, pada tanaman umur 18 tahun rata-rata produktivitas preminya sebesar 126,27 Kg/hari, dan pada tanaman umur 24 tahun rata-rata produktivitas premi pemanen sebesar $129,60 \mathrm{Kg} /$ hari. Basis untuk setiap kelompok umur tanaman ditentukan berdasarkan topografi lahan dan tinggi tanaman. Misalnya, apabila lahan yang memiliki kemiringan yang curam dan pohon sawitnya tinggi seperti pada tanaman umur 24 tahun, maka perusahaan menetapkan basis panen sebesar 650 $\mathrm{Kg} /$ hari. Hal ini merupakan suatu kebijakan dari perusahaan karena dengan kondisi lahan yang curam dan pohon tinggi lebih beresiko daripada lahan yang datar atau sedikit bergelombang dengan tanaman yang pendek.

\section{Faktor-Faktor yang Mempengaruhi Produktivitas Tenaga Pemanen Sawit.}

Variabel-variabel bebas yang diduga berpengaruh terhadap produktivitas tenaga pemanen sawit adalah: umur pemanen $(X 1)$, jumlah tanggungan keluarga (X2), pendidikan formal (X3), umur tanaman (X4), pengalaman kerja (X5). Hasil estimasinya disajikan pada Tabel 4.

Tabel 4. Hasil estimasi faktor-faktor yang mempengaruhi produktivitas tenaga pemanen sawit

\begin{tabular}{clccc}
\hline No. & \multicolumn{1}{c}{ Variabel Bebas } & $\begin{array}{c}\text { Koefisien } \\
\text { Regresi }\end{array}$ & $\begin{array}{c}\text { Std. } \\
\text { Error }\end{array}$ & T-hitung \\
\hline 1 & Umur pemanen (X1) & 2,604 & 0,760 & $3,428^{*}$ \\
2 & Jumlah tanggungan keluarga (X2) & 5,375 & 2,296 & $2,341^{*}$ \\
3 & Pendidikan formal (X3) & 1,006 & 0,824 & 1,222 \\
4 & Umur tanaman (X4) & $-0,809$ & 0,467 & $-1,730$ \\
5 & Pengalaman kerja (X5) & 2,056 & 1,304 & 1,577 \\
6 & Intersep & 18,216 & & \\
7 & R $2=18,216$ & & & \\
8 & F-hitung $=73,610$ & & & \\
9 & T-tabel untuk 95\% (a/2=0,025)=2,27 & & & \\
10 & F-tabel untuk 95\%=1,44 & &
\end{tabular}

Sumber : Data primer diolah, 2010

Keterangan: $\left(^{*}\right)$ berpengaruh nyata pada tingkat signifikan 95\%

38 | Ronika Nainggolan, Agus Purwoko, dan M. Zulkarnain Yuliarso. Faktor ... 
Nilai intersep menunjukkan bahwa tanpa adanya variabel-variabel bebas (umur pemanen, jumlah tanggungan keluarga, pendidikan formal, umur tanaman, dan pengalaman kerja), maka produktivitas tenaga kerja pemanen sawit akan menurun. Dari nilai $\mathrm{R}^{2}$ di atas dapat dijelaskan bahwa semua variabel bebas yang digunakan secara bersama-sama memberikan sumbangan sebesar 73,8 persen terhadap variasi naik turunnya produktivitas tenaga pemanen sawit, sedangkan sisanya sebesar 26,2 persen dipengaruhi oleh faktorfaktor lainnya yang tidak diikut sertakan dalam penelitian ini. Uji signifikansi memperlihatkan bahwa F-hitung $(81,52)$ lebih besar dari F-tabel $(2,26)$. Hal ini menunjukkan secara bersama-sama variabel-variabel bebas berpengaruh nyata terhadap produktivitas tenaga pemanen sawit pada PT. Bio Nusantara Teknologi Bengkulu.

Berdasarkan hasil estimasi di atas, maka dapat dituliskan suatu persamaan regresi berganda sebagai berikut:

$$
\begin{gathered}
Y=18,216+2,604 X_{1}+5,375 X_{2}+1,006 X_{3}-0,809 X_{4}+2,056 X_{5} \\
(0,760) \quad(2,296) \quad(0,824) \quad(0,467) \quad(1,304)
\end{gathered}
$$

Uji t untuk masing-masing variabel bebas terhadap variabel terikat adalah sebagai berikut:

\section{Umur Pemanen}

Hasil analisis menunjukkan bahwa koefisien regresi variabel umur pemanen adalah bernilai 2,064. Uji t menunjukkan bahwa nilai $t_{\text {hitung }}(3,428)>$ $t_{\text {tabel }}(2,26)$. Hal ini berarti Ho ditolak dan Ha diterima artinya umur pemanen berpengaruh nyata terhadap produktivitas tenaga pemanen sawit. Hasil perhitungan memperlihatkan adanya korelasi yang positif sehingga dapat diindikasikan bahwa semakin tua umur pemanen sawit maka semakin tinggi pula tingkat produktivitas kerja dari pemanen sawit tersebut. Kondisi ini dapat dijelaskan bahwa semakin tua umur tenaga pemanen, maka pemanen semakin terampil dalam memanen tandan buah segar sehingga jumlah tbs yang dipanen juga akan semakin banyak.

\section{Jumlah Tanggungan Keluarga}

Hasil analisis memperlihatkan bahwa koefisien regresi variabel jumlah tanggungan keluarga adalah bernilai 5,375. Uji $t$ menunjukkan bahwa nilai $t_{\text {hitung }}(2,341)>t_{\text {tabel }}(2,26)$, sehingga jumlah tanggungan keluarga berpengaruh nyata terhadap produktivitas tenaga pemanen sawit. Semakin banyak jumlah tanggungan keluarga maka semakin tinggi tingkat produktivitas kerja dari pemanen sawit tersebut, atau sebaliknya.

Dari hasil wawancara ditemukan bahwa sebagian pemanen mengatakan bahwa giat atau tidaknya mereka dalam bekerja memanen sawit ternyata 
dipengaruhi oleh banyak atau sedikitnya jumlah tanggungan keluarga, karena semakin banyak jumlah tanggungan keluarga mereka maka mereka harus selalu berusaha memenuhi kebutuhan anggota keluarga sesuai dengan kemampuan yang dimilikinya.

Hasil penelitian ini bertentangan dengan penelitian Riyadi (2002) yang menyatakan bahwa jumlah tanggungan keluarga tidak mempunyai hubungan yang nyata dengan tingkat produktivitas tenaga kerja pemetik teh pada PTPN VII (Persero) Unit Pagar Alam. Banyak atau sedikitnya jumlah anggota keluarga mereka akan tetap melaksanakan pekerjaan sebagai pemetik teh.

\section{Pendidikan formal}

Hasil analisis menunjukkan bahwa koefisien regresi variabel pendidikan formal adalah bernilai 1,006. Hasil uji t menunjukkan bahwa nilai $t_{\text {hitung }}(1,222)<$ $t_{\text {tabel }}(2,26)$. Ini berarti Ha ditolak dan Ho diterima, sehingga pendidikan formal tidak berpengaruh nyata terhadap tingkat produktivitas tenaga pemanen sawit di PT. Bio Nusantara Teknologi Bengkulu.

Hasil pengamatan di lapangan memberikan indikasi bahwa tinggi atau rendahnya pendidikan formal tidak dijadikan indikator dalam penerimaan tenaga pemanen sawit di PT. Bio Nusantara Teknologi Bengkulu. Hal ini dikarenakan untuk kegiatan memanen sawit lebih difokuskan pada keterampilan, kemampuan serta kekuatan tenaga kerja dalam kegiatan memanen sawit. Hasil penelitian ini sejalan dengan penelitian Yuliarso (1998) yang menyatakan bahwa tingkat pendidikan formal tidak berpengaruh nyata karena kegiatan pemetikan teh pada PT Sarana Mandiri Mukti di Kab. Kepahiang.

\section{Umur Tanaman}

Hasil analisis menunjukkan bahwa koefisien regresi variabel umur tanaman adalah bernilai $-0,089$. Hasil uji $\mathrm{t}$ memperlihatkan bahwa nilai $\mathrm{t}_{\text {hitung }}(-$ $1,730)>-t_{\text {tabel }}(-2,26)$. Hal ini berarti variabel umur tanaman tidak berpengaruh nyata terhadap produktivitas tenaga pemanen sawit. Hasil perhitungan menunjukkan adanya korelasi yang negatif sehingga memberikan indikasi bahwa semakin tua umur tanaman maka semakin rendah tingkat produktivitas tenaga pemanen sawit (lihat Tabel 1).

Hasil penelitian ini sejalan dengan dengan hasil penelitian Andriani (2008) tentang produktivitas tenaga kerja pemanen sawit di PT. Daria Dharma Pratama bahwa umur tanaman tidak berpengaruh nyata terhadap produktivitas. Walaupun umur sawit berbeda tetapi semuanya masih dalam kategori umur produktif, sehingga hal ini tidak akan mempengaruhi hasil panen yang diperoleh oleh pemanen sawit.

40 | Ronika Nainggolan, Agus Purwoko, dan M. Zulkarnain Yuliarso. Faktor ... 


\section{Pengalaman Kerja}

Hasil analisis menunjukkan bahwa koefisien regresi variabel pengalaman kerja adalah sebesar bernilai 2,056. Hasil uji t menunjukkan bahwa nilai thitung $(1,577)<t_{\text {tabel }}(2,26)$. Hal ini berarti pengalaman kerja tidak berpengaruh nyata terhadap produktivitas kerja pemanen sawit di PT. Bio Nusantara Teknologi Bengkulu. Hal ini dikarenakan untuk kegiatan memanen sawit, selain diperlukan pengalaman kerja juga dibutuhkan keterampilan, kemampuan dan kekuatan untuk kegiatan memanen sawit. Tenaga pemanen yang masih berusia muda mempunyai kekuatan fisik yang lebih dibandingkan pemanen berusia tua, sehingga hasil panenannya menjadi lebih banyak meskipun pengalaman kerja masih sedikit. Sebaliknya, tenaga pemanen yang berusia tua dan berpengalaman belum tentu mempunyai produktivitas yang tinggi.

\section{KESIMPULAN DAN SARAN}

\section{Simpulan}

1. Rata-rata produktivitas (premi produksi) tenaga pemanen sawit pada PT. Bio Nusantara Teknologi Bengkulu adalah 130,314 kg/hari. Produktivitas pemanen berdasarkan umur tanaman yang dipanen, adalah: 133,46 kg/hari (umur tanaman 12 tahun), 126,27 kg/hari (umur tanaman 18 tahun), dan $129,60 \mathrm{~kg} /$ hari (umur tanaman 24 tahun).

2. Faktor-faktor yang berpengaruh nyata terhadap produktivitas tenaga pemanen sawit adalah umur pemanen dan jumlah tanggungan keluarga.

\section{Saran}

Jam kerja yang digunakan oleh pemanen masih terlalu sedikit. Jam kerja yang ditetapkan oleh perusahaan yakni 07.00-14.00 WIB, akan tetapi pemanen hanya bekerja sampai pukul 12.00 WIB saja setelah mereka mendapatkan sedikit premi. Sebaiknya pemanen sawit dapat memaanfaatkan waktunya untuk bekerja memanen sawit lebih banyak karena ancak yang disedikan untuk setiap pemanen cukup luas, sehingga akan mendapatkan premi produksi yang banyak atau pendapatan pemanen dapat meningkat.

\section{DAFTAR PUSTAKA}

Andriani. 2008. Faktor-faktor yang Mempengaruhi Produktivitas Pemanen Tenaga Kerja Sawit di PT. Daria Dharma Pratama di Ipuh Kecamatan mukomuko Selatan Kabupaten Mukomuko. Skripsi. Jurusan Sosial Ekonomi Pertanian, Fakultas Pertanian, Universitas Bengkulu (tidak dipublikasikan). 
Daniar, R. R.. 2006. Analisis Produktivitas dan Pendapatan Buruh Panen Peserta Sistem Integrasi Sawit Sapi (SISS) di PT. Agricinal Kabupaten Bengkulu Utara. Skripsi. Jurusan Sosial Ekonomi Pertanian, Fakultas Pertanian, Universitas Bengkulu (tidak dipublikasikan).

Mardiana. 2001. Faktor-faktor Penentu Tingkat Produktivitas Tenaga Kerja Pemanen Sawit (Studi Kasus pada PT. Agromuko Estate Air Dikit Kecamatan Mukomuko Utara Kabupaten Bengkulu Utara). Skripsi. Jurusan Sosial Ekonomi Pertanian, Fakultas Pertanian, Universitas Bengkulu (tidak dipublikasikan).

Riyadi, M. Teri. 2002. Analisis Faktor-faktor yang Berhubungan dengan Produktivitas Tenaga Kerja Pemetik Teh di PTP Nusantara VI (persero) Unit Usaha Pagar Alam. Skripsi. Jurusan Sosial Ekonomi Pertanian, Fakultas Pertanian, Universitas Bengkulu (tidak dipublikasikan).

Sedarmayanti. 2001. Sumber Daya Manusia dan Produktivitas Kerja. CV. Mandar Maju, Bandung.

Setiowati. 2007. Faktor-Faktor yang Berhubungan dengan Produktivitas dan Kontribusi Penghasilan Tenaga Kerja Wanita Pemetik Teh Di PTP. Nusantara VI Kayu Aro Kabupaten Kerinci Propinsi Jambi. Skripsi. Jurusan Sosial Ekonomi Pertanian, Fakultas Pertanian, Universitas Bengkulu (tidak dipublikasikan).

Sinungan, M. 1992. Manajemen Modern. Gunung Agung, Jakarta

Yuliarso, M. Zulkarnain. 1998. Faktor-Faktor yang Mempengaruhi Produktivitas Wanita Pemetik Teh di PT. Sarana Mandiri Mukti Kepahiang. Skripsi. Jurusan Sosial Ekonomi Pertanian, Fakultas Pertanian, Universitas Bengkulu (tidak dipublikasikan).

42 | Ronika Nainggolan, Agus Purwoko, dan M. Zulkarnain Yuliarso. Faktor ... 